\title{
PERAN ENVIRONMENTAL PERFORMANCE TERHADAP KINERJA PERUSAHAAN DENGAN CORPORATE SOCIAL RESPONSIBILITY SEBAGAI VARIABEL MEDIASI
}

\author{
Aisha Hanif ${ }^{1}$, Hadiah Fitriyah ${ }^{2}$, Rizky Eka Febriansah ${ }^{3}$ \\ 1,2,3 Universitas Muhammadiyah Sidoarjo, Sidoarjo, Indonesia \\ Email: aishahanif@umsida.ac.id
}

\begin{abstract}
This study aims to determine the role of environmental performance on company performance with corporate social responsibility as a mediating variable. This research was conducted on all manufacturing companies that participated in the company performance rating (PROPER) program and companies listed on the Indonesia Stock Exchange during the period 2016-2018. The research method used is to use PLS (Partial Least Squares), namely SEM (Structural Equation Method) based on variance. The results of this study indicate that environmental performance has no effect on financial performance, environmental performance has an effect on corporate social responsibility, corporate social responsibility has no effect on financial performance, corporate social responsibility is unable to mediate the effect of environmental performance on corporate financial performance. The results of this study have implications for the company, namely as an evaluation material for companies in order to increase the quantity and quality of environmental management and their social responsibility activities so as to obtain positive feedback from the community and ultimately improve company performance which is proxied by increased corporate profits.
\end{abstract}

Keywords: corporate social responsibility, environmental performance, financial performance

\section{ABSTRAK}

Penelitian ini bertujuan untuk mengetahui peran environmental performance terhadap kinerja perusahaan dengan corporate social responsibility sebagai variabel mediasi. Penelitian ini dilakukan kepada seluruh perusahaan manufaktur yang mengikuti program penilaian peringkat kinerja perusahaan (PROPER) dan perusahaan yang terdaftar di Bursa Efek Indonesia selama periode tahun 2016-2018. Metode penelitian yang digunakan adalah menggunakan PLS (Partial Least Squares) yaitu SEM (Structural Equation Method) berdasarkan varians. Hasil dari penelitian ini menyebutkan bahwa environmental performance tidak berpengaruh terhadap financial performance, environmental performance berpengaruh terhadap corporate social responsibility, corporate social responsibility tidak berpengaruh terhadap kinerja keuangan, corporate social responsibility tidak mampu memediasi pengaruh environmental performance terhadap kinerja keuangan perusahaan. Hasil penelitian ini memiliki implikasi bagi perusahaan yaitu sebagai bahan evaluasi bagi perusahaan agar meningkatkan kuantitas serta kualitas dari pengelolaan lingkungan dan kegiatan tanggung jawab sosial mereka sehingga memperoleh timbal balik yang positif dari masyarakat dan akhirnya dapat meningkatkan kinerja perusahaan yang diproksi oleh meningkatnya laba perusahaan.

Kata kunci: kinerja keuangan, kinerja lingkungan, tanggung jawab sosial perusahaan

\section{KETERANGAN ARTIKEL}

Riwayat Artikel: diterima: 8 Agustus 2020; direvisi: 14 Desember 2020; disetujui: 21 Desember 2020

Klasifikasi JEL: Q51, Q56

Cara Mensitasi: Hanif, A., dkk. (2020). Peran Environmental Performance terhadap Kinerja Perusahaan dengan Corporate Social Responsibility sebagai Variabel Mediasi. JIAFE (Jurnal IImiah Akuntansi Fakultas Ekonomi), 6(2), 199-208. https://doi.org/10.34204/jiafe.v6i2.2264

Copyright@2020. JIAFE (Jurnal Akuntansi Ilmiah Fakultas Ekonomi) Universitas Pakuan 


\section{PENDAHULUAN}

Kinerja keuangan merupakan gambaran tentang informasi mengenai kegiatan yang sudah dilakukan oleh sebuah organisasi bisnis dan informasi mengenai pencapaian yang telah diraih oleh organisasi tersebut. Pencapaian yang diraih oleh suatu bisnis perusahaan dapat dilihat dari laba yang dihasilkan oleh perusahaan tersebut. Pengelolaan dalam penggunaan laba yang bertujuan untuk mengukur kinerja keuangan sangat diperlukan oleh perusahaan untuk keberlangsungan hidup suatu perusahaan (Jayati, 2016), prinsip untuk mendapatkan keuntungan yang besar sering diabaikan oleh perusahaan, seperti ketidakefektifan manajemen, serta pengabaian terhadap pelestarian dan kinerja lingkungan (Hastawati dan Sarsiti, 2016). Tujuan serta ambisi dari perusahaan guna mendapatkan keuntungan ini membuat masyarakat sebagai stakeholder menginginkan agar perusahaan lebih peduli terhadap kesejahteraan masyarakat dan dampak-dampak yang mungkin mengemuka akibat dari kegiatan yang dilakukan oleh perusahaan (Rahmawati, 2012). Selama ini para investor maupun shareholder hanya melihat kinerja keuangan sebagai satu-satunya tolak ukur kinerja sebuah perusahaan, padahal kinerja non-keuangan juga dapat menggambarkan kinerja dari perusahaan.

Enviromental performance atau kinerja lingkungan perusahaan dapat dinilai melalui program yang telah dicanangkan oleh pemerintah melalui Kementrian Lingkungan Hidup pada tahun 2002 yaitu Program Penilaian Peringkat Kinerja Perusahaan dalam Pengelolaan Lingkungan Hidup (PROPER). Perusahaan yang memiliki kinerja lingkungan yang baik akan mengurangi dampak sosial yang terjadi di masyarakat sehingga kepercayaan masyarakat terhadap perusahaan menjadi meningkat dan dapat menghasilkan keuntungan finansial bagi perusahaan (Rahmawati, 2012). Dalam melakukan pengelolaan lingkungan dan menghadapi dampak yang ditimbulkan kepada lingkungan sekitar, tentunya diperlukan biaya lingkungan, alokasi pengeluaran biaya yang didedikasikan untuk melakukan pengelolaan lingkungan dapat menunjukkan konsistensi dari perusahaan dalam hal kepedulian lingkungan sehingga dapat membangun kepercayaan dari masyarakat terhadap tanggung jawab sosial perusahaan (Tunggal dan Fachrurrozie, 2014).

Tanggung jawab sosial perusahaan diatur dalam Peraturan Pemerintah Republik Indonesia Nomor 47 Tahun 2012 mengenai Tanggung Jawab Sosial dan Lingkungan Perseroan Terbatas. Tanggung jawab sosial dan lingkungan perusahaan adalah tanggung jawab perusahaan kepada pemegang saham dan karyawan meliputi profitabilitas perusahaan dan bentuk kemajuan, serta tanggung jawab pihak eksternal terkait pembayaran pajak dan penyediaan lapangan kerja, peningkatan kesejahteraan dan kemampuan masyarakat sekitar, serta menjaga lingkungan untuk generasi mendatang (Susanto, 2009). Perusahaan yang menjalankan tanggung jawab sosial juga akan mendapatkan reputasi yang baik di masyarakat (Angela, 2015). Selain itu dengan banyaknya bermunculan isu mengenai pelestarian lingkungan dan manajemen bisnis hijau, maka meningkatkan tuntutan bagi pelau bisnis untuk meningkatkan tanggung jawab sosial perusahaan dan lingkungan (Chuang dan Huang, 2018).

Beberapa peneliti terdahulu telah membahas mengenai hubungan antara tanggung jawab sosial perusahaan dan kinerja keuangan mempengaruhi kinerja keuangan (Putra, 2018. Sedangkan penelitian Parengkuan (2017) dan Kraus (2020) menegaskan bahwa tanggung jawab sosial perusahaan tidak berdampak pada kinerja keuangan. Terkait dengan hubungan antara kinerja lingkungan dan tanggung jawab sosial perusahaan, penelitian yang dilakukan oleh (Cahyani dan Bahri, 2018) menyebutkan bahwa kinerja lingkungan memiliki pengaruh yang signifikan terhadap tanggung jawab 
sosial perusahaan sedangkan pada penelitian (Putra, 2017) menyatakan bahwa kinerja lingkungan tidak berpengaruh signifikan terhadap tanggung jawab sosial perusahaan. Sedangkan pada penelitian Handayati (2017) menyatakan bahwa kinerja lingkungan yang diukur dengan variabel PROPER memiliki pengaruh yang signifikan terhadap pengungkapan tanggung jawab sosial. Jurnal internasional pada penelitian (Nurlaila, dkk; 2017) menjelaskan bahwa enviromental performance influences corporate social and enviromental disclousure. Berdasarkan latar belakang diatas maka perlu adanya telaah kembali terkait dengan Peran environmental performance terhadap kinerja perusahaan dengan corporate social responsibility sebagai variabel Mediasi terutama pada perusahaan manufaktur yang terdaftar di Bursa Efek Indonesia.

\section{KAJIAN LITERATUR DAN PENGEMBANGAN HIPOTESIS}

\section{Pengaruh Kinerja Lingkungan terhadap Kinerja Keuangan}

Kinerja lingkungan merupakan kinerja perusahaan dalam menciptakan lingkungan yang baik (Suratno dkk, 2006). Upaya perusahaan untuk menciptakan lingkungan yang baik dengan melakukan aktivitas dan menggunakan bahan yang tidak merusak lingkungan (Rahma, 2013). Perlindungan dan pengelolaan lingkungan hidup adalah upaya sistematis dan terpadu yang dilakukan untuk melestarikan fungsi lingkungan hidup dan mencegah adanya pencemaran lingkungan hidup yang meliputi pencemaran, pemanfaatan, pengendalian, pemeliharaan, pengawasan, dan penegakan hukum. (UU RI No. 32 Tahun 2009 tentang Perlindungan dan Pengelolaan Lingkungan Hidup pasal 1 poin 2). Kinerja lingkungan perusahaan diukur dari pencapaian perusahaan dalam mengikuti program PROPER yang merupakan salah satu struktur yang didorong oleh Kementerian Lingkungan Hidup (KLH) untuk mendorong perusahaan melakukan pengelolaan lingkungan melalui perangkat informasi (Suratno dkk, 2006). Penelitian terdahulu dari Natalia dkk (2013) menyebutkan bahwa kinerja lingkungan memiliki pengaruh yang signifikan terhadap kinerja keuangan. Oleh karena itu, hipotesis pertama dari penelitian ini adalah sebagai berikut.

\section{$\mathrm{H}_{1}$ : Kinerja Lingkungan berpengaruh signifikan terhadap Kinerja Keuangan}

\section{Pengaruh Kinerja Lingkungan terhadap Corporate social responsibility}

Tanggung Jawab Sosial Perusahaan berkaitan dengan bagaimana perusahaan mengelola proses bisnis agar memiliki dampak positif secara keseluruhan bagi masyarakat (Hadi, 2014). Tanggung jawab sosial dan lingkungan perusahaan telah diatur dalam Undangundang Perseroan Terbatas No.40 Pasal 74 tahun 2007 (Untung, 2008). CSR adalah suatu komitmen yang harus dimiliki oleh perusahaan untuk melakukan kontribusi terhadap pengembanga ekonomi yang berkelanjutan dan memperhatikan tanggung jawab sosialnya (Untung, 2008).

Perseroan dapat mengungkapkan penerapan tanggung jawab sosial perusahaan melalui laporan keuangan tahunan perusahaan, yang didalamnya meliputi laporan tanggung jawab sosial perusahaan selama satu tahun berturut-turut. (Sari, 2012). Tanggung jawab sosial perusahaan merupakan komitmen perusahaan untuk berkontribusi pada pembangunan ekonomi yang berkelanjutan dengan memperhatikan tanggung jawab sosial perusahaan dan mengedepankan keseimbangan antara aspek ekonomi, sosial dan lingkungan (Untung, 2008). Tanggung jawab sosial perusahaan adalah suatu konsep yang diharapkan dapat menjadi sebuah alternative terobosan baru dalam pemberdayaan masyarakat miskin (Untung, 2008).

Penelitian terdahulu yang dilakukan oleh Cahyani dan Bahri (2018) kinerja 
lingkungan memiliki pengaruh signifikan terhadap tanggung jawab sosial perusahaan sedangkan penelitian Putra (2017) menyatakan bahwa kinerja lingkungan tidak berpengaruh signifikan terhadap tanggung jawab sosial perusahaan. Sedangkan penelitian Handayati (2015) menyatakan bahwa kinerja lingkungan yang diproksi dengan PROPER menunjukkan pengaruh signifikan terhadap pengungkapan tanggung jawab sosial. Oleh karena itu, hipotesis kedua dari penelitian ini adalah sebagai berikut.

$\mathrm{H}_{2}$ : Kinerja Lingkungan berpengaruh signifikan terhadap corporate social responsibility

\section{Pengaruh Corporate social responsibility terhadap Kinerja Keuangan}

Indikator kinerja perusahaan dibedakan menjadi dua jenis, yaitu indikator keuangan dan indikator non keuangan. Indikator keuangan sebenarnya menunjukkan berbagai perilaku yang terjadi di luar sektor keuangan. Peningkatan pengembalian keuangan merupakan hasil dari berbagai kinerja operasi, termasuk peningkatan kepercayaan konsumen terhadap produk atau layanan perusahaan, peningkatan efektivitas biaya proses bisnis internal perusahaan yang digunakan untuk menghasilkan produk, serta peningkatan produktivitas dan keterlibatan karyawan.

Kinerja keuangan merupakan analisis untuk melihat sejauh mana perusahaan telah menerapkan aturan pelaksanaan keuangan yang sesuai dengan standar dan ketentuan Standar Akuntansi Keuangan (Fahmi, 2012). Kinerja keuangan merupakan hasil atau pencapaian yang dicapai oleh manajemen perusahaan dalam pelaksanaan efektif fungsi manajemen aset perusahaan dalam jangka waktu tertentu.

Penelitian terdahulu menyatakan tanggung jawab sosial perusahaan memiliki pengaruh yang signifikan terhadap kinerja keuangan (Cahyani dan Bahri, 2018; Putra, 2017). Sedangkan pada penelitian Parengkuan (2017) menyatakan bahwa tanggung jawab sosial perusahaan tidak berpengaruh terhadap kinerja keuangan. Oleh karena itu, hipotesis ketiga dari penelitian ini adalah sebagai berikut.

$\mathrm{H}_{3}$ : corporate social responsibility berpengaruh signifikan terhadap kinerja keuangan

\section{Pengungkapan corporate social responsibility} (CSR) memediasi hubungan antara kinerja lingkungan dengan kinerja keuangan

Hasil penelitian Cahyani dan Bahri (2018) menyatakan bahwa tanggung jawab sosial perusahaandapat memediasi pengaruh hubungan antara kinerja lingkungan dengan kinerja keuangan. Penelitian Angela (2015) menunjukkan bahwa pengungkapan tanggung jawab sosial perusahaan akan menjadi variabel perantara antara kinerja lingkungan dan kinerja keuangan. Oleh karena itu, hipotesis keempat dari penelitian ini adalah sebagai berikut.

$\mathrm{H}_{4}$ : corporate social responsibility memediasi hubungan antara kinerja lingkungan dan kinerja keuangan

\section{METODE PENELITIAN}

Penelitian ini merupakan penelitian deskriptif kuantitatif. Populasi dalam penelitian ini adalah seluruh perusahaan manufaktur yang mengikuti program penilaian peringkat kinerja perusahaan (PROPER) dan perusahaan yang terdaftar di Bursa Efek Indonesia selama periode tahun 2016-2018. Pengambilan sampel menggunakan teknik purposive sampling dan dihasilkan 44 emiten sebagai sampel. Penelitian ini menggunakan data sekunder. Metode analisis yang digunakan dalam penelitian ini adalah dengan menggunakan PLS (Partial Least Squares) yaitu SEM (Structural Equation Method) berdasarkan varians. 
Tabel 1. Kriteria Pemilihan Sampel

\begin{tabular}{|c|c|}
\hline Kriteria & Jumlah \\
\hline $\begin{array}{l}\text { Populasi Perusahaan manufaktur } \\
\text { yang terdaftar di BEI tahun 2016- } \\
2018\end{array}$ & 143 \\
\hline $\begin{array}{l}\text { Perusahaan manufaktur secara } \\
\text { berturut-turut melaporkan laporan } \\
\text { keuangan pada tahun 2016, 2017, } \\
\text { dan } 2018\end{array}$ & 117 \\
\hline $\begin{array}{l}\text { Laporan keuangan yang } \\
\text { menggunakan Rupiah }\end{array}$ & 73 \\
\hline $\begin{array}{l}\text { Perusahaan yang melaporkan } \\
\text { Corporate social responsibility }\end{array}$ & 73 \\
\hline $\begin{array}{l}\text { Perusahaan manufaktur yang } \\
\text { mengikuti program PROPER tahun } \\
2016,2017 \text {, dan } 2018\end{array}$ & 44 \\
\hline $\begin{array}{l}\text { Total perusahaan manufaktur yang } \\
\text { memenuhi kriteria }\end{array}$ & 44 \\
\hline
\end{tabular}

\section{Kinerja Lingkungan}

Data kinerja lingkungan menggunakan data laporan PROPER (Rencana Evaluasi Kinerja Pengelolaan Lingkungan) dari laman kementrian lingkungan hidup. Cara penghitungan PROPER menggunakan skor penilaian berdasarkan realisasi nilai warna PROPER perusahaan manufaktur. Jika perusahaan mendapat peringkat warna tertinggi yaitu emas maka diberikan skor 5, skor 4 untuk warna hijau, skor 3 untuk warna biru, skor 2 untuk warna merah, dan skor 1 untuk warna hitam. Kelima warna ini mewakili sistem peringkat kinerja PROPER.

\section{Kinerja Keuangan}

Kinerja keuangan dapat diukur melalui laporan keuangan tahunan, yang memberikan tinjauan berkala atas status keuangan perusahaan. Investor menggunakan informasi yang terdapat dalam laporan keuangan untuk memprediksi imbal hasil, dividen serta risiko (Natalia dkk, 2013). Indikator kinerja keuangan dalam penelitian ini diproksikan dengan Return on Asset (ROA) dan Debt to Equity Ratio (DER) (Samsul, 2018).

$$
R O A=\frac{\text { Laba Bersih }}{\text { Total Aset }}
$$

dan

$$
D E R=\frac{\text { Total Utang }(\text { Debt })}{\text { Ekuitas (Equity) }}
$$

\section{Corporate Social Responsibility}

Tanggung jawab sosial dan lingkungan perusahaan tertera dan diatur dalam Undangundang Perseroan Terbatas No. 40 Pasal 74 tahun 2007 (Untung, 2017). Tanggung jawab sosial perusahaan merupakan komitmen yang harus dimiliki perusahaan untuk berkontribusi pada pembangunan ekonomi yang berkelanjutan dan memperhatikan tanggung jawab sosialnya (Untung, 2017). Variabel ini diproksikan dengan menggunakan indikator Global Reporting Initiatives (GRI) dan diukur menggunakan formula sebagai berikut.

$$
C S D=\frac{n}{K}
$$

CSD adalah index pengungkapan tanggung jawab sosial perusahaan, $\mathrm{N}$ adalah item yang telah diungkapkan oleh perusahaan, dan $\mathrm{K}$ adalah jumlah item yang seharusnya diungkapkan oleh perusahaan.

\section{HASIL DAN PEMBAHASAN}

\section{Convergent validity}

Validitas konvergensi digunakan untuk mengukur keberlakuan hasil pengukuran variabel indikator dan menjelaskan konsep teoritis keberadaan indikator tersebut. Uji ini dengan melihat hasil dari uji outer loadings. 
Aisha Hanif: Peran Environmental Performance ...

Tabel 2. Outer Loadings

\begin{tabular}{c|c}
\hline \multicolumn{2}{c}{ Environmental Performance } \\
\hline Indikator & Outer Loadings \\
\hline EP & 1,000 \\
\hline \multicolumn{2}{c}{ Corporate social responsibility } \\
\hline CSR & 1,000 \\
\hline Kinerja Keuangan (Financial Performance) \\
\hline FP1 & 0,633 \\
\hline FP2 & 0,769 \\
\hline
\end{tabular}

Berdasarkan tabel diatas menunjukkan bahwa indikator environmental performance (EP), corporate social responsibility (CSR) dan financial performance 1 (FP2) memiliki validitas yang baik karena memiliki skor uji loading factor menunjukkan angka diatas 0,7, sedangkan financial performance 2 (FP2) nilai loading factornya kurang dari 0,7 , sehingga indicator FP2 dinyatakan tidak valid, oleh karena itu perlu di uji kembali.

Tabel 3. Outer Loadings

\begin{tabular}{c|c}
\hline \multicolumn{2}{c}{ Environmental Performance } \\
\hline Indikator & Outer Loadings \\
\hline EP & 1,000 \\
\hline Corporate social responsibility \\
\hline CSR & 1,000 \\
\hline Kinerja Keuangan (Financial \\
Performance) \\
\hline FP2 & 1,000 \\
\hline
\end{tabular}

Hasil outer loading setelah dilakukan pengujian kembali menunjukkan bahwa indicator EP, CSR dan FP2 menunjukkan nilai outer loading diatas 0,7 , Hal tersebut menunjukkan bahwa indikator tersebut sangat efektif dan dapat dilanjutkan ke pengujian selanjutnya.

\section{Discriminat Validity}

Validitas diskriminan adalah untuk mengukur derajat perbedaan indikator dalam struktur instrumen. Untuk menguji validitas diskriminan dapat dilakukan dengan melakukan pengecekan cross loading.
Tabel 4. Cross Loading

\begin{tabular}{c|r|r|r}
\hline & \multicolumn{1}{|c|}{ CSR } & \multicolumn{1}{c|}{ EP } & \multicolumn{1}{c}{ FP } \\
\hline CSR & $\mathbf{1 , 0 0 0}$ & $-0,198$ & 0,033 \\
\hline EP & $-0,198$ & $\mathbf{1 , 0 0 0}$ & $-0,065$ \\
\hline FP2 & 0,033 & $-0,065$ & $\mathbf{1 , 0 0 0}$ \\
\hline
\end{tabular}

Tabel 4 menunjukkan bahwa dibandingkan dengan nilai beban variabel laten lainnya, nilai faktor beban setiap indikator dari masingmasing variabel laten memiliki nilai faktor beban terbesar.

\section{Composite Reliability}

Kriteria validitas dan reliabilitas dapat dilihat dari nilai konstruk dan nilai rata-rata ekstraksi varian (AVE) masing-masing konstruk. Jika nilainya 0,7 dan AVE lebih besar dari 0,50 berarti struktur memiliki keandalan yang tinggi.

Tabel 5. Composite Reliability dan Average Variance Extracted

\begin{tabular}{l|r|r}
\hline & $\begin{array}{c}\text { Composite } \\
\text { Reliability }\end{array}$ & $\begin{array}{c}\text { Average Variance } \\
\text { Extracted (AVE) }\end{array}$ \\
\hline CSR & 1,000 & 1,000 \\
\hline EP & 1,000 & 1,000 \\
\hline FP & 1,000 & 1,000 \\
\hline
\end{tabular}

\section{Inner Model}

Gambar berikut merupakan diagram jalur yang dilengkapi dengan koefisien jalur yang menjelaskan hubungan antar variabel.

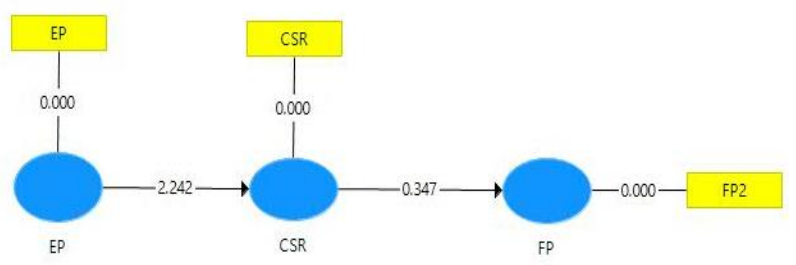

Gambar 1. Koefisien Jalur

Pengujian Hipotesis

Pengaruh Kinerja Lingkungan terhadap Kinerja Keuangan

Berikut hasil pengujian hipotesis disajikan dalam tabel model struktural. 
Tabel 6. Model Struktural

\begin{tabular}{cccccc}
\hline & $\begin{array}{c}\text { Origin } \\
\text { al } \\
\text { Sampl } \\
\text { e } \\
\text { (O) }\end{array}$ & $\begin{array}{c}\text { Sampl } \\
\text { e } \\
\text { Mean } \\
\text { (M) }\end{array}$ & $\begin{array}{c}\text { Std } \\
\text { Dev } \\
\text { (STDE } \\
\text { V) }\end{array}$ & $\begin{array}{c}\text { T } \\
\text { Statisti } \\
\text { cs } \\
\text { (IO/ } \\
\text { STDEV } \\
\text { ) }\end{array}$ & $\begin{array}{c}\text { Palu } \\
\text { es }\end{array}$ \\
\hline EP-> FP & $-0,018$ & $-0,074$ & 0,133 & 0,138 & 0,890 \\
\hline $\begin{array}{c}\text { EP -> } \\
\text { CSR }\end{array}$ & $-0,198$ & $-0,196$ & 0,089 & 2,224 & 0,027 \\
\hline $\begin{array}{c}\text { CSR -> } \\
\text { FP }\end{array}$ & 0,009 & 0,078 & 0,090 & 0,097 & 0,923 \\
\hline EP_CSR & $-0,002$ & $-0,016$ & 0,022 & 0,077 & 0,939 \\
\hline FP & & & & & \\
\hline
\end{tabular}

Hasil uji hipotesis menunjukkan bahwa kinerja lingkungan tidak berpengaruh terhadap kinerja keuangan, dengan nilai $\mathrm{P}$ 0,890 dan nilai t 0,138 . Perusahaan dianggap sebagai organisasi yang harus mematuhi aturan sosial untuk memastikan diakui oleh masyarakat dan dapat terus eksis (Tunggal dan Fachrurrozie, 2014). Hal ini berarti bahwa informasi mengenai kinerja lingkungan sebuah perusahaan dapat memengaruhi penilaian para shareholder sehingga perusahaan akan mengungkapkannya di pengungkapan tanggung jawab sosial perusahaan.

Berkaitan dengan hal tersebut, meskipun peran enviromental performance terhadap kinerja keuangan ini sangat penting bagi perusahaan untuk menjaga nama baik perusahaan, namun melalui hasil data penelitian ini dapat diketahui bahwa enviromental performance tidak berpengaruh terhadap financial performance. Hal ini menguatkan penelitian yang dilakukan oleh Yudi Pratama Putra yang menyatakan bahwa Kinerja lingkungan tidak memiliki pengaruh yang signifikan terhadap kinerja keuangan (Putra, 2017).

\section{Pengaruh Kinerja Lingkungan terhadap corporate social responsibility}

Hasil pengujian koefisien jalur berdasarkan nilai $P$ sebesar 0,027 dan nilai $t$ sebesar 2,224 menunjukkan bahwa tingkat pengaruh kinerja lingkungan yang signifikan terhadap tanggung jawab sosial perusahaan. Hal ini menunjukkan bahwa kinerja lingkungan merupakan bagian penting dari sistem pengelolaan lingkungan (Putri, 2017). Pada UU No.40 tahun 2007 dijelaskan bahwa Perseroan terbatas yang menjalankan bisnis atau kegiatan komersial yang berkaitan dengan sumber daya alam harus memenuhi tanggung jawab sosial dan lingkungan (pasal 74) dan seluruh perseroan terbatas wajib memberikan informasi pemenuhan tanggung jawab sosial dan lingkungan dalam laporan tahunan RUPS direksi (pasal 66).

UU No. 40 Tahun 2007 dikuatkan oleh Peraturan Pemerintah No.47 Tahun 2012 tentang Pelaksanaan Tanggung Jawab Sosial dan Lingkungan Perseroan (TJSLP) dan pada tahun 2012 perseroan wajib untuk melaksanakan hal tersebut. Hasil pengujian ini selaras dengan hasil penelitian yang dilakukan oleh Nurlaila, dkk (2017) yang menyebutkan bahwa Kinerja Lingkungan dapat mempengaruhi pengungkapan sosial dan lingkungan perusahaan dan penelitian yang dilakukan oleh Cahyani dan Bahri (2018) yang menegaskan bahwa Kinerja Lingkungan memiliki pengaruh yang signifikan terhadap tanggung jawab sosial perusahaan. Sehingga dapat disimpulkan hipotesis pada penelitian ini diterima.

\section{Pengaruh Corporate Social Responsibility terhadap Kinerja Keuangan}

Nilai nilai yang diketahui dari hasil uji hipotesis yaitu sebesar 0,923 dan nilai t sebesar 0,097, menjelaskan bahwa Corporate social responsibility tidak signifikan terhadap financial performance. Hal ini menjelaskan bahwa kegiatan tanggung jawab sosial yang dilakukan perusahaan tidak mampu memengaruhi kemampuan perusahaan dalam menghasilkan laba. Kinerja keuangan merupakan salah satu indikator utama untuk mengukur keberhasilan suatu perusahaan, selama ini karena kinerja keuangan 
merupakan faktor utama suatu perusahaan, maka kinerja keuangan banyak digunakan oleh perusahaan.

Hasil uji hipotesis diatas tidak sejalan dengan penelitian yang dilakukan oleh Putra (2017) dan Lin, dkk (2015) yang menyatakan bahwa variabel Corporate social responsibility berpengaruh signifikan terhadap kinerja keuangan. Sehingga dapat disimpulkan bahwa hipotesis dalam penelitian ini ditolak.

Pengungkapan corporate social responsibility (CSR) memediasi hubungan antara kinerja lingkungan dengan kinerja keuangan

Hasil pengujian hipotesis menunjukkan bahwa nilai $P$ sebesar 0,939 dan nilai t 0,077 . Hal ini menunjukkan bahwa tanggung jawab sosial perusahaan tidak memediasi dampak kinerja lingkungan terhadap kinerja keuangan. Hal ini menunjukkan bahwa aktivitas perusahaan dalam melakukan tanggung jawab sosialnya belum mendapatkan timbal balik yang positif dari masyarakat atau belum ada dampak nyata dari kegiatan CSR tersebut. Kegiatan CSR yang dilakukan perusahaan dianggap belum mampu meningkatkan legitimasi dari masyarakat.

Selain itu, kegiatan CSR perusahaan dianggap belum dapat meningkatkan kegiatan perusahaan dalam mengelola lingkungan hidup. Hal tersebut menjadi alasan perusahaan belum mampu meningkatkan citra positifnya di mata masyarakat. Hasil ini memperkuat penelitian yang dilakukan oleh Meiyana dan Aisyah (2019) yang menunjukkan bahwa kinerja lingkungan tidak mempengaruhi kinerja keuangan dan tidak dapat diatur oleh tanggung jawab sosial perusahaan.

\section{PENUTUP}

Hasil penelitian menunjukkan bahwa pertama environmental performance (EP) tidak berpengaruh terhadap financial performance. $\mathrm{Hal}$ ini karena aspek penilaian PROPER tidak langsung menyentuh kepentingan masyarakat dan hasil dari kinerja lingkungan tersebut tidak dapat dirasakan secara langsung oleh masyarakat sehingga perusahaan tidak mampu menciptakan hubungan timbal balik dengan masyarakat. Kedua, environmental performance berpengaruh terhadap corporate social responsibility yang mengindikasikan bahwa penilaiaian kinerja lingkungan oleh KLH akan memberikan pengungkapan sosial yang lebih luas pada perusahaan. Ketiga, corporate social responsibility tidak berpengaruh terhadap financial performance dan corporate social responsibility tidak mampu memediasi pengaruh environmental performance terhadap kinerja keuangan perusahaan. Hal ini menunjukkan bahwa aktivitas perusahaan dalam melakukan tanggung jawab sosialnya belum mendapatkan timbal balik yang positif dari masyarakat sehingga kegiatan corporate social responsibility ini belum mampu meningkatkan legitimasi dari masyarakat dan meningkatkan kegiatan perusahaan dalam mengelola lingkungan hidup yang dapat membuat perusahaan belum mampu meningkatkan citra positifnya di mata masyarakat.

Hasil penelitian ini memiliki implikasi khususnya bagi perusahaan. Dengan melihat bahwa hasil kinerja lingkungan dan pengungkapan tanggung jawab sosial perusahaan tidak berpengaruh terhadap kinerja keuangan perusahaan dapat menjadi bahan evaluasi bagi perusahaan agar meningkatkan kuantitas serta kualitas dari pengelolaan lingkungan dan kegiatan tanggung jawab sosial mereka sehingga memperoleh timbal balik yang positif dari masyarakat dan akhirnya dapat meningkatkan kinerja perusahaan yang diproksi oleh meningkatnya laba perusahaan.

\section{REFERENSI}

Abdillah, Willy dan Jogiyanto. (2015). Partial Least Square (PLS) Alternatif Structural Equation Modeling (SEM) dalam Penelitian Bisnis. Ed.1. Yogyakarta: ANDI.

Angela. (2015). Pengaruh Kinerja Lingkungan terhadap Kinerja Finansial dengan 
Pengungkapan Corporate social responsibility (CSR) Sebagai Variabel Intervening. Skripsi. Universitas Sanata Dharma

Cahyani, F. A. dan Bahri, S. (2017). Pengaruh Kinerja Lingkungan Terhadap Corporate Financial Performance Dengan Corporate social responsibility Disclosure Sebagai Variabel Intervening (Studi Empiris Pada Perusahaan Manufaktur Yang Terdaftar Di Bei). Ekonika: Jurnal Ekonomi Universitas Kadiri, 1(2), 117-142.

Chuang, SP. dan Huang, S.J. (2018). The Effect of Environmental Corporate Social Responsibility on Environmental Performance and Business Competitiveness: The Mediation of Green Information Technology Capital. J Bus Ethics 150(6), 991-1009.

Handayati, P. (2017). Analisis Kinerja Lingkungan dan Mekanisme GCG Terhadap Pengungkapan Pertanggungjawaban Sosial. Jurnal Akuntansi Aktual, 4(1), 58-68.

Hastawati, R. R., dan Sarsiti. (2016). Pengaruh Kinerja Lingkungan dan Corporate social responsibility (CSR) Terhadap Kinerja Keuangan Pada Perusahaan Manufaktur yang Terdaftar di Bursa Efek Indonesia Tahun 2011-2013. Jurnal Penelitian dan Kajian IImiah Universitas Surakarta, 14 (4), 49-59.

Husillos, J. (2008). A Stakeholder-Theory Approach to Environmental Disclousures by Small and Medium Enterprises (SMES). Revista de Contabilidad: Spanish Accounting Review, 11(1), 125-156.

Jayati, S.E. (2016). Pengaruh Intellectual Capital Terhadap Kinerja Keuangan Perusahaan Perdagangan Jasa yang Terdaftar di Bursa Efek Indonesia. Skripsi. Universitas Negeri Yogyakarta.

Kraus, S., dkk. (2020). Corporate Social Responsibility and Environmental
Performance: The Mediating Role Of Environmental Strategy And Green Innovation. Technological Forecasting and Social Change, 160, 120262.

Lin, C. S., dkk. (2015). An integrated model to explain how corporate social responsibility affects corporate financial performance. Sustainability, 7(7), 82928311.

Meiyana, A. dan Aisyah, M.N. (2019). Pengaruh Kinerja Lingkungan, Biaya Lingkungan, Dan Ukuran Perusahaan Terhadap Kinerja Keuangan Dengan Corporate social responsibility Sebagai Variabel Intervening. Nominal, Barometer Riset Akuntansi aan Manajemen, 8(1).

Natalia, dkk. (2013). The Effect of Environmental Performance and Corporate social responsibility Disclosure on Financial Performance (Study on Basic Industry and Chemical Companies Listed on Indonesia Stock Exchange). Jurnal Ilmiah Mahasiswa $F E B, 2(2)$.

Nurlaila, dkk. (2017). The Influence of Stakeholder Pressure and Environmental Performance on Corporate Social and Enviromental Disclosure and its Implication on the Value of the Firm. International Journal of Economic Research, 14(15), 353-369.

Parengkuan, W. (2017). Pengaruh Corporate social responsibility(csr) Terhadap Kinerja Keuangan Perusahaan Manufaktur Yang Terdaftar Di Bursa Efek Indonesia Melalui Pojok Bursa Feb - Unsrat. Jurnal Riset Ekonomi, Manajemen, Bisnis Dan Akuntansi, 5(2), 564-571.

Putra, Y. P. (2018). Pengaruh Kinerja Lingkungan terhadap Kinerja Keuangan Dengan Pengungkapan Corporate Social responsibility (CSR) sebagai Variabel Intervening. BALANCE Jurnal Akuntansi Dan Bisnis, 2(2), 227. 
Putri, V. K., dan Indriana I. (2017). Apakah Manajemen Lingkungan Perlu Diimplementasikan Dalam Menciptakan Kinerja LIngkungan yang Baik dan KInerja Keuangan yang Optimal?. Tirtayasa Ekonomika, 12(2), 232-251.

Rahmawati, A. dan Achmad, T. (2012). Pengaruh Kinerja Lingkungan terhadap Financial Corporate Performance dengan Corporate Social Responsibility Disclosure sebagai Variabel Intervening. Diponegoro Journal Of Accounting, Vol 1, No.2, 1-15.

Samsul, M. (2018). Pasar Modal dan Manajemen Portofolio. Jakarta: Erlangga.

Suratno, dkk. (2006). Pengaruh Environmental Performance terhadap Environmental
Disclosure dan Economic Performance (Studi Empiris pada Perusahaan Manufaktur yang Terdaftar Di Bursa Efek Jakarta Periode 2001-2004). Simposium Nasional Akuntansi 9 Padang, 23-26 Agustus 2006.

Susanto, A. B. (2009). Reputation Driven Corporate social responsibility Pendekatan Strategic Management dalam CSR. Jakarta: Esensi Erlangga.

Tunggal W.S.P. dan Fachrurrozie. (2014). Pengaruh Environmental Performance, Environmental Cost dan CSR Disclosure Terhadap Financial Performance. Accounting Analysis Journal, 3 (3), 310320.

Untung, H. B. (2008). Corporate social responsibility. Jakarta: Sinar Grafika 